\title{
Sea-Salt Aerosol Mass Concentration Oscillations after Rainfall, Derived from Long-Term Measurements in Lampedusa (Central Mediterranean)
}

\author{
P. Kishcha, ${ }^{1}$ B. Starobinets, ${ }^{1}$ R. Udisti, ${ }^{2}$ S. Becagli, ${ }^{2}$ A. di Sarra, ${ }^{3}$ D. Sferlazzo, ${ }^{3}$ \\ C. Bommarito, ${ }^{3}$ and P. Alpert ${ }^{1}$ \\ ${ }^{1}$ Department of Geophysical, Atmospheric, and Planetary Sciences, Tel Aviv University, 69978 Tel Aviv, Israel \\ ${ }^{2}$ Department of Chemistry, University of Florence, 50019 Florence, Italy \\ ${ }^{3}$ Laboratory for Earth Observations and Analyses, National Agency for New Technologies, Energy, \\ and Economic Sustainable Development, 00123 Rome, Italy
}

Correspondence should be addressed to P. Kishcha, pavel@cyclone.tau.ac.il

Received 3 February 2012; Accepted 27 February 2012

Academic Editors: V. Amiridis, M. Boy, and P. Zanis

Copyright $\odot 2012$ P. Kishcha et al. This is an open access article distributed under the Creative Commons Attribution License, which permits unrestricted use, distribution, and reproduction in any medium, provided the original work is properly cited.

\begin{abstract}
Sea-salt aerosol (SSA) is the dominant contributor to cloud condensation nuclei over ocean areas, where wind speed is significant. Thereby, SSA could affect cloud formation and play an important role in the Earth weather and climate. Rainfall could produce large impact on SSA concentration due to wet removal processes. An analysis of changes in sea-salt aerosol concentration after rainfall is essential for a deeper understanding of the process of SSA loading in the boundary layer. The current experimental study focused on analyzing time variations of SSA mass concentration after rainfall, on the basis of long-term daily SSA measurements during the three-year period 2006-2008, at the tiny Mediterranean island of Lampedusa (Central Mediterranean). To study the effect of rainfall on SSA time variations, we used the superposed epoch method. We applied this approach to differing rainfall events related to different months and atmospheric/sea conditions. Integrated processing was applied to SSA concentration anomalies, in order to filter out random variability. Observational evidence of SSA mass concentration oscillations after rainfall with a maximum on the 2 nd day and a minimum on the 4 th day was obtained. The knowledge of SSA variations after rainfall is important for validating rainout parameterization in existing sea-salt aerosol and climate models.
\end{abstract}

\section{Introduction}

Sea-salt aerosol (SSA) is generated by various physical processes, especially by the direct injection of sea-spray aerosols into the atmosphere through breaking waves during whitecap formation [1-4], resulting in a strong dependence of the SSA production flux on wind speed. The oceans are the largest source of aerosols by mass to the atmosphere $[3,5]$. Sea-salt aerosol plays an important role in the Earth climate: SSA may be the dominant contributor to cloud nuclei in those regions of the marine atmosphere where wind speeds are significant [6].

Many publications have discussed the observed relationship between SSA concentration and sea surface wind $[2,3]$. According to [2], wind speed is the dominant factor controlling wave generation and subsequent breaking.
Rainfall can have a large impact on SSA concentration. After a rainfall event, the concentration of SSA particles is lower than it was previously [3]. Giorgi and Chameides [7, 8] analyzed a wet removal process of highly soluble aerosols by using model simulations. They found that the wet removal process is complex: it depends not only on the amount of precipitation, but also on the duration and frequency of precipitation events.

Our study focuses on investigating time variations in surface sea-salt aerosol mass concentration after rainfall. To our knowledge, so far, no experimental research on this topic has been carried out. This is an experimental study based on daily sea-salt aerosol measurements, at the Mediterranean island of Lampedusa, during the three-year period 20062008. In order to analyze SSA mass concentration variations after rainfall, we applied the superposed epoch method, 
which was frequently applied to studying the time variation of geophysical data $[9,10]$. The idea of this method is to analyze many different observations of the same event and to look for responses to that same event. In the current study, the superposed epoch method was applied to various rainfall events related to differing months and atmospheric conditions. We attempted to find some common features in SSA time variations after different rainfall cases. Variations of SSA concentrations on the 1st, 2nd, 3rd, 4th, and 5 th days after rainfall have been analyzed. We found that these variations show oscillating behavior of SSA mass concentrations after rainfall.

\section{Data and Methodology}

The current study of temporal variations of SSA concentrations after precipitation was based on daily ground-based measurements in Lampedusa, in the Central Mediterranean (Figure 1). Lampedusa, which measures several kilometers across, is located far from continental areas and large islands and is characterized by clean air without industrial pollution. The sea-salt aerosol monitoring site $\left(35^{\circ} 31^{\prime} \mathrm{N} ; 12^{\circ} 38^{\prime} \mathrm{E}\right)$ is located at approximately $10 \mathrm{~m}$ from the north-east coastline of Lampedusa, at $50 \mathrm{~m}$ elevation (Figure 1). The longterm ground-based PM10 measurements used are suitable for analyzing aerosol particles with size less than $10 \mu \mathrm{m}$. According to Clarke et al. [11], SSA particles with size within the range of $0.1-10 \mu \mathrm{m}$ dominate marine aerosol mass. Consequently, the PM10 measurements used are suitable for analyzing SSA mass concentration changes.

Sea-salt aerosol mass concentrations were determined by means of the chemical composition analysis of PM10 aerosol measurements on a daily basis, over the two-year period, from January 2007 to December 2008. In addition, 73 daily PM10 measurements, taken on a random basis in the year 2006, were used in the current study.

Aerosols were sampled on Teflon filters with an EN 12341 sampler with a PM10 preselected cut-off head. Samples were collected over 24 hour periods, with the start time of 00:01 UTC. SSA at Lampedusa was calculated as the sum of the weight of $\mathrm{ssNa}^{+}$(i.e., sea salt $\mathrm{Na}^{+}$) $, \mathrm{Cl}^{-}, \mathrm{ssMg}^{2+}, \mathrm{ssCa}^{2+}$, and $\mathrm{ssSO}_{4}{ }^{2-}$. The fraction $\mathrm{ssNa}^{+}$and $\mathrm{ssCa}^{2+}$ was calculated by the following equations:

(i) $s s \mathrm{Na}=\mathrm{Na}-\mathrm{nssNa}=\mathrm{Na}-\mathrm{nssCa}^{*}(\mathrm{Na} / \mathrm{Ca})_{\text {crust }}$,

(ii) $\mathrm{nssCa}=\mathrm{Ca}-\mathrm{ssCa}=\mathrm{Ca}-\mathrm{ssNa}^{*}(\mathrm{Ca} / \mathrm{Na})_{\text {seawater }}$,

(iii) $(\mathrm{Na} / \mathrm{Ca})_{\text {crust }}=0.56[\mathrm{w} / \mathrm{w}]$ (Bowen, [12]),

(iv) $(\mathrm{Ca} / \mathrm{Na})_{\text {seawater }}=0.038[\mathrm{w} / \mathrm{w}]($ Bowen, [12]),

where $\mathrm{Na}$ and $\mathrm{Ca}$ represent the total concentration of these elements actually measured in the samples, $(\mathrm{Na} / \mathrm{Ca})_{\text {crust }}$ is the mean ratio in the Earth crust, $(\mathrm{Ca} / \mathrm{Na})_{\text {seawater }}$ the mean ratio in bulk seawater, ss and nss stand for sea salt and nonsea salt,respectively. Ratios are expressed as weight on weight $[\mathrm{w} / \mathrm{w}]$. In the Lampedusa aerosol, the $\mathrm{ss} \mathrm{Na}^{+}$is $96 \%$ of the total $\mathrm{Na}^{+}$, while the $\mathrm{ssCa}^{2+}$ is only $20 \%$ of the $\mathrm{Ca}^{2+}$ budget. After $\mathrm{ssNa}^{+}$calculation, the $\mathrm{ssMg}^{2+}$ and $\mathrm{ssSO}_{4}{ }^{2-}$ contributions were evaluated by their ratios in sea water $\left(\mathrm{Mg} / \mathrm{Na}=0.129 \mathrm{w} / \mathrm{w}\right.$ and $\left.\mathrm{SO}_{4} / \mathrm{Mg} 0.253 \mathrm{w} / \mathrm{w}\right)$.

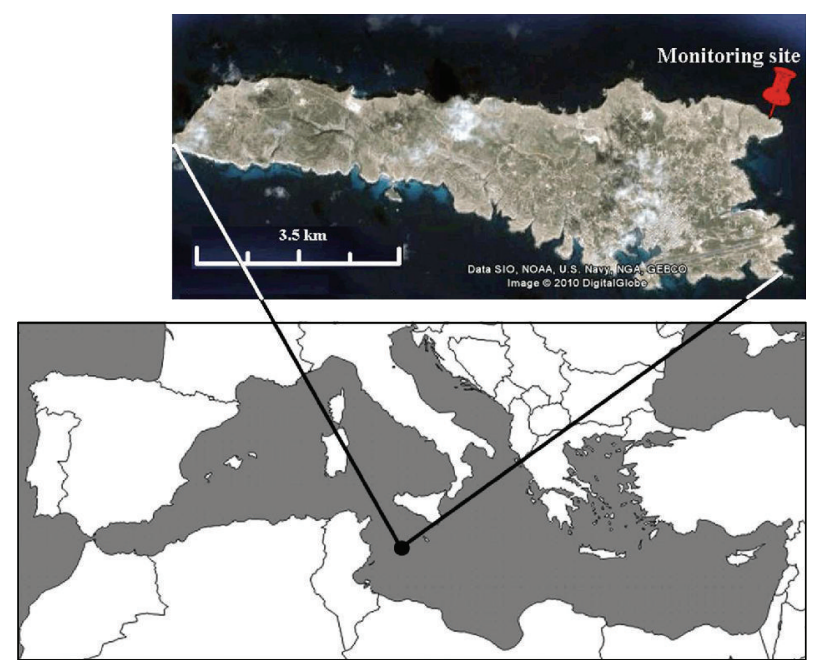

Figure 1: A map of the Mediterranean Sea and a map of the island of Lampedusa with the monitoring site (the grey place mark).

It is known that $\mathrm{Cl}^{-}$in atmospheric particulate undergoes depletion processes, mainly due to exchange reactions with $\mathrm{H}_{2} \mathrm{SO}_{4}$ and $\mathrm{HNO}_{3}$, leading to reemission of $\mathrm{HCl}$ in the atmosphere. Besides, $\mathrm{Cl}^{-}$losses from the filter surface can be caused by reactions between $\mathrm{Cl}^{-}$(from sea-salt aerosol) and anthropogenic combustion products (such as $\mathrm{NOx}, \mathrm{O}_{3}$, $\mathrm{HO}$, and $\mathrm{HO}_{2}$ radicals), producing atomic chlorine [13, 14]. In such aged sea spray aerosol, the $\mathrm{Cl} / \mathrm{Na}$ ratio is lower than that found for fresh sea spray aerosol. At Lampedusa, the sampling site is near to the sea spray source; therefore, this effect can be considered negligible. At Lampedusa, extra sources for $\mathrm{Cl}^{-}$are sporadic. Therefore, $s s \mathrm{Na}^{+}$and $\mathrm{Cl}^{-}$are reliable markers for the evaluation of SSA content. Details of sea-salt aerosol measurements in Lampedusa were described by Becagli et al. [15], Fattori et al. [16], Udisti et al. [17], and Kishcha et al. [18].

SSA concentrations on rainless days after rain events, measured over the three-year period under consideration, were analyzed. This analysis was carried out by creating a data set of SSA concentration on the 1st, 2nd, 3rd, 4th, and 5th rainless days separately. Available SSA data after rainfall were limited; therefore, we were not able to analyze SSA concentrations on the sixth, seventh, and following days separately. Rain events followed by only one rainless day were eliminated from our analysis.

Throughout the current study, we use the terminology "consecutive 1st, 2nd, 3rd, 4th, and 5th days after rainfall" for days following each other in chronological order, because they relate to the same rainfall events. We use the terminology "nonconsecutive days after rainfall" for days not following each other in chronological order and relating to different rainfall events. SSA measurements on nonconsecutive days after rainfall were used in order to increase the statistics and to base our results on a wide range of cases.

Hereafter, if not explicitly specified, we refer to SSA measurements on both consecutive and nonconsecutive days. 
TABLE 1: Descriptive statistics of differences between SSA concentrations on consecutive days after rainfall.

\begin{tabular}{lccc}
\hline Parameter & Total number of days & Number of positive differences (percentage) & Number of negative differences (percentage) \\
\hline DELTA $_{2-1}$ & 28 & $16(57 \%)$ & $12(43 \%)$ \\
DELTA $_{3-2}$ & 26 & $7(27 \%)$ & $19(73 \%)$ \\
DELTA $_{4-3}$ & 17 & $4(24 \%)$ & $13(76 \%)$ \\
DELTA $_{5-4}$ & 10 & $6(60 \%)$ & $4(40 \%)$ \\
\hline
\end{tabular}

Sea-salt aerosols from a relatively large surrounding area could be collected on the filter during the 24-hour sampling period. Therefore, we consider that rain measurements over this relatively large territory are more representative than local rain measurements. Specifically, daily accumulated Tropical Rainfall Measuring Mission (TRMM) rainfall data from the $3 \mathrm{~B} 42 \mathrm{~V} 6$ archive, on a $0.25^{\circ} \times 0.25^{\circ}$ latitudelongitude grid [19], were used to select rainy days with daily accumulated rainfall over $0.5 \mathrm{~mm}$. The daily accumulated rainfall was averaged over the circular area of a $50-\mathrm{km}$ radius, centered at the monitoring site in Lampedusa. The analyzed rain events were characterized by a range of daily accumulated rainfall from $0.5 \mathrm{~mm}$ to $44.9 \mathrm{~mm}$.

\section{Results}

In order to study variations of sea-salt aerosol mass concentration on the 1st, 2nd, 3rd, 4th, and 5th days after rainfall, two different approaches have been applied to available SSA measurements: (a) analyzing differences between SSA concentrations on consecutive days (Section 3.1) and (b) using the superposed epoch method together with integrated processing, which eliminated monthly/seasonal and random variability (Sections 3.2-3.4).

3.1. Analysis of Differences between SSA Concentrations on Consecutive Days after Rainfall. First, we analyzed differences between SSA concentrations measured on the first and second consecutive days after rainfall $\left(\right.$ DELTA $_{2-1}$ means that SSA concentrations on the first day were subtracted from those on the second day). The use of SSA differences allowed us to analyze and to compare SSA changes after rainfall in different months and seasons. Figure 2(a) represents a dependence of DELTA $2-1$ on wind speed averaged for the first and second days: 28 couples of consecutive first and second days after rainfall were used. One can see that for weak winds less than $5 \mathrm{~m} / \mathrm{s}$, there are approximately the same number of positive and negative differences. For stronger winds over $5 \mathrm{~m} / \mathrm{s}$, the number of positive differences is twice that of negative ones. The predominance of positive DELTA $_{2-1}$ values over negative ones was not caused by an increase in wind speed: the average wind speed on the second day $(5.2 \mathrm{~m} / \mathrm{s})$ was lower than that on the first day $(5.6 \mathrm{~m} / \mathrm{s})$.

A similar approach was used for analyzing differences in SSA concentration between the third and second days $\left(\right.$ DELTA $\left._{3-2}\right)$, the fourth and third days $\left(\right.$ DELTA $\left._{4-3}\right)$, and between the fifth and fourth days $\left(\right.$ DELTA $\left._{5-4}\right)$ (Table 1). As shown in Figure 2(b), either for weak winds $(<5 \mathrm{~m} / \mathrm{s})$ or for stronger winds $(>5 \mathrm{~m} / \mathrm{s})$, negative DELTA $_{3-2}$ values dominate positive ones. The predominance of negative DELTA $_{3-2}$ values over positive ones suggests that, on the third day, dry deposition dominates SSA production. The analysis of differences in SSA concentration between the fourth and third days showed that negative values of DELTA $_{4-3}$ dominate positive ones, in a similar way to DELTA 3-2 (Figure 2(c)). This indicates that dry deposition dominates SSA production even on the fourth day. One can see, however, that differences in SSA concentration between the fifth and fourth days $\left(\right.$ DELTA $\left._{5-4}\right)$ are mainly positive (Figure $2(\mathrm{~d})$ and Table 1 ). This suggests that sea-salt aerosol production on the fifth day dominates dry deposition.

Therefore, the obtained differences in SSA concentrations point to SSA mass concentration oscillations after rainfall. Note, that these SSA concentration oscillations are observed in the presence of strong random variability in SSA concentrations. These oscillations will be analyzed in detail in Sections 3.2-3.4 by applying integrating processing in order to remove random variability.

3.2. SSA Concentration Anomalies. In order to illustrate variations of SSA concentration after rainfall, the SSA data sets, created for the first, second, and third days are displayed in Figures 3(a), 3(c), and 3(e). Strong variability of SSA concentration can be seen. This means that SSA concentrations could differ significantly under the same wind speed. As SSA concentrations depend on wind speed, we have compared the data sets for the same interval of wind speed. For the whole period under consideration in the current study, the range of wind speed observed on all the days after rainfall was from $1.9 \mathrm{~m} / \mathrm{s}$ to $13.4 \mathrm{~m} / \mathrm{s}$. The wind speed range observed on the second day after rainfall, from $2.8 \mathrm{~m} / \mathrm{s}$ to $9.9 \mathrm{~m} / \mathrm{s}$, was narrower than the wind speed range observed on other days after rainfall. Therefore, the comparison between SSA data sets was carried out specifically for that wind speed range (Figure 3).

The relatively high standard deviation (Table 2) indicates, however, a high variability of SSA concentrations, as seen in Figure 3. This variability occurs because not only is the desired effect of rainfall on SSA variations included in the used SSA data sets, but other effects are also included. Some of those effects could be due to differing initial conditions for after rainfall events in different months and seasons. In order to remove the latter effects, we used SSA concentration anomalies, which are a deviation of SSA concentrations from their monthly mean level. Examples of the SSA anomaly data sets obtained separately for the first, second, and third days after rainfall are shown in Figures 3(b), 3(d), and 3(f). Note 
TABLE 2: Parameters of the data sets of SSA mass concentration on the first, second, third, fourth, and fifth rainless days after rainfall within the wind speed range $2.8 \mathrm{~m} / \mathrm{s}-9.9 \mathrm{~m} / \mathrm{s}$.

\begin{tabular}{|c|c|c|c|c|c|}
\hline Day after rainfall & 1st day & 2nd day & 3rd day & 4th day & 5th day \\
\hline Number of days & 38 & 44 & 30 & 19 & 19 \\
\hline Average SSA concentration, $\mu \mathrm{g} / \mathrm{m}^{3}$ & 8.7 & 9.0 & 8.2 & 6.9 & 8.8 \\
\hline Standard deviation of SSA, $\mu \mathrm{g} / \mathrm{m}^{3}$ & 4.6 & 5.2 & 5.3 & 4.6 & 5.3 \\
\hline Average wind speed, $\mathrm{m} / \mathrm{s}$ & 6.1 & 5.5 & 6.2 & 5.6 & 5.9 \\
\hline
\end{tabular}

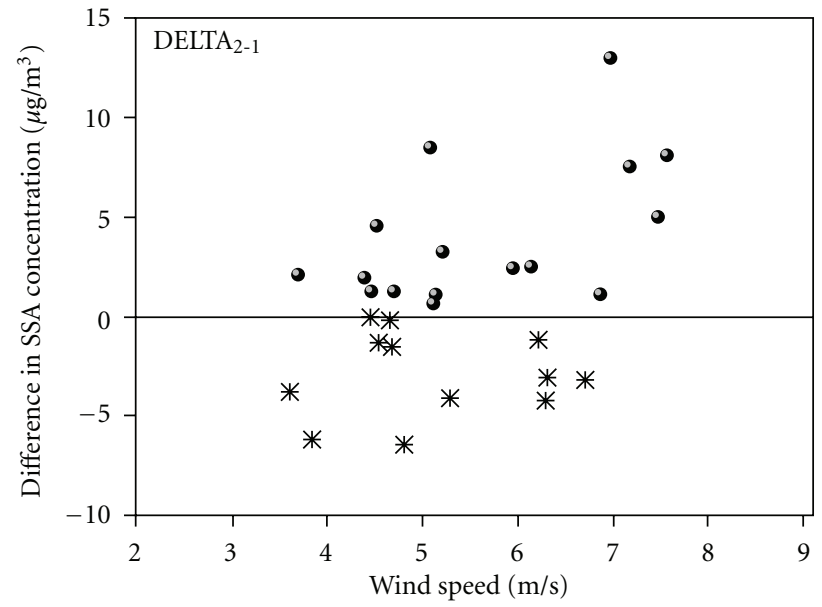

(a)

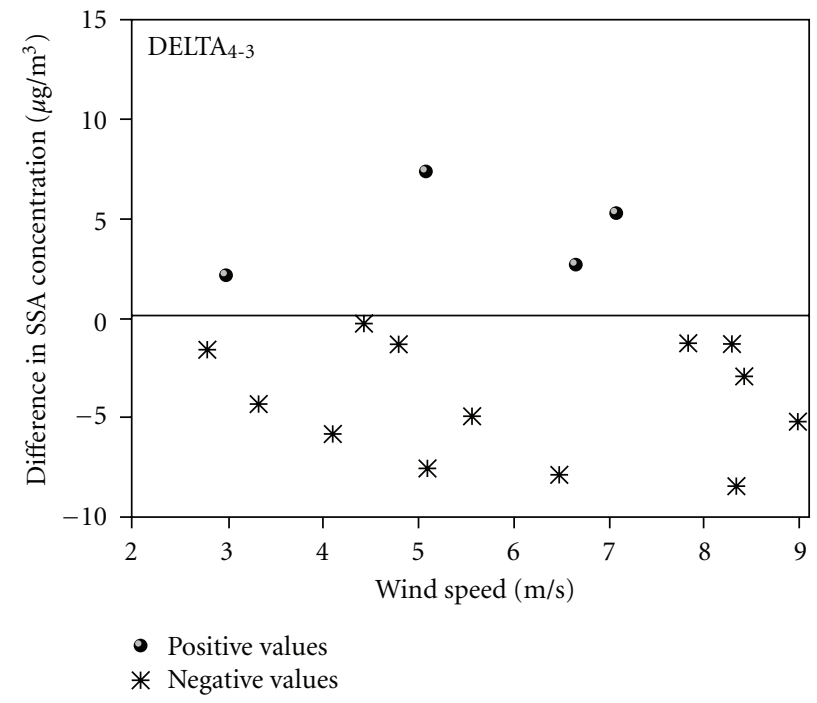

(c)

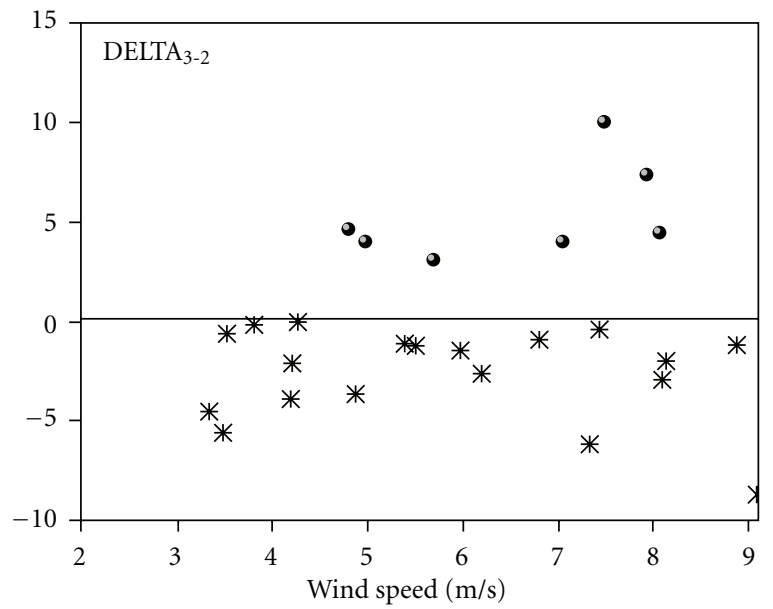

(b)

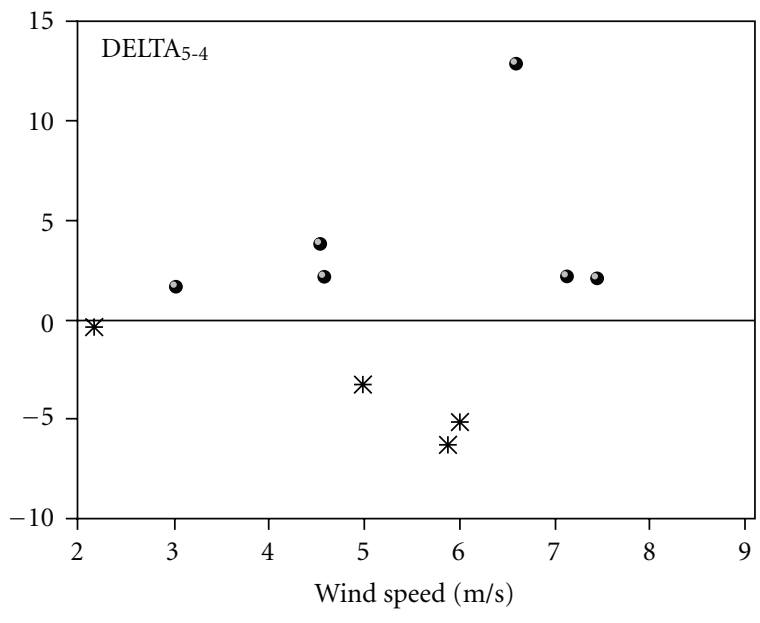

- Positive values

* Negative values

(d)

FIGURE 2: Differences in SSA concentrations between consecutive days after rainfall as a function of wind speed, averaged for those days: (a) between the second and first consecutive days $\left(\right.$ DELTA $_{2-1}$ means that SSA concentrations on the first day were subtracted from those on the second day) (28 cases); (b) between the third and second consecutive days (DELTA $3-2)(26$ cases); (c) between the fourth and third consecutive days $\left(\right.$ DELTA $\left._{4-3}\right)$ (17 cases); $(\mathrm{d})$ between the fifth and fourth consecutive days $\left(\mathrm{DELTA}_{5-4}\right)(10$ cases $)$.

that high random variability is observed in SSA anomalies on each of the specified days after rainfall, much as it was seen in the original SSA concentrations (Figure 3). As described below, in order to filter out random variability, integrated processing was applied to SSA anomalies. Thus, the use of SSA anomalies allowed us to remove monthly/seasonal variability, while the use of integrated processing allowed us to remove random variability.

3.3. Changes in the Cumulative Horizontal SSA Flux on the 1st and 2nd Days after Rainfall. One can expect that the effect of rainfall on SSA time variations after rainfall is significant 


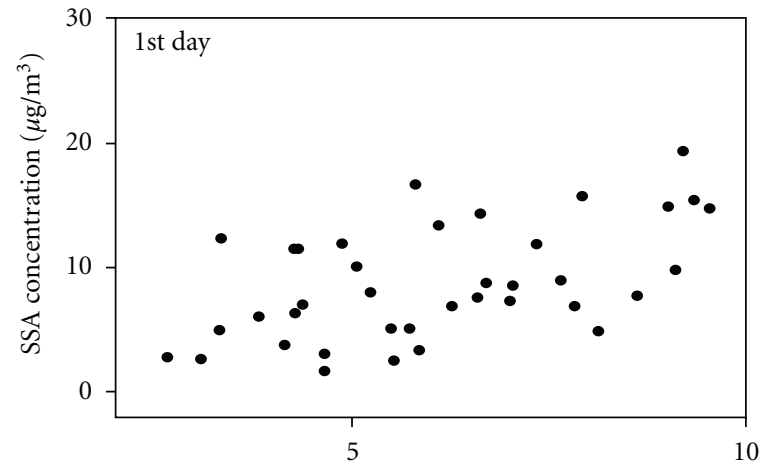

(a)

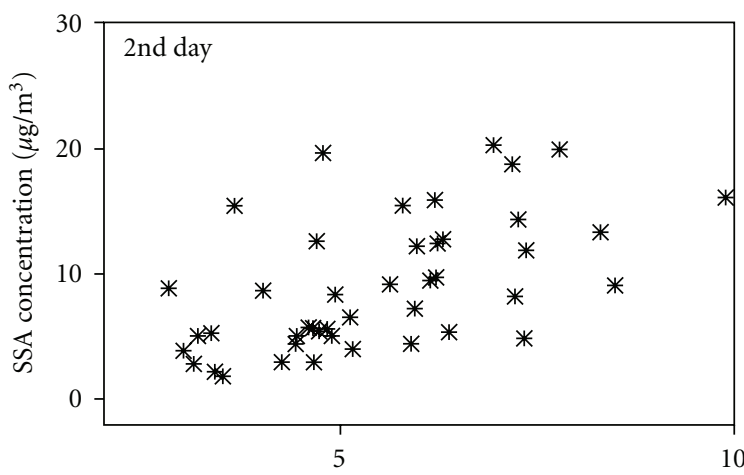

(c)

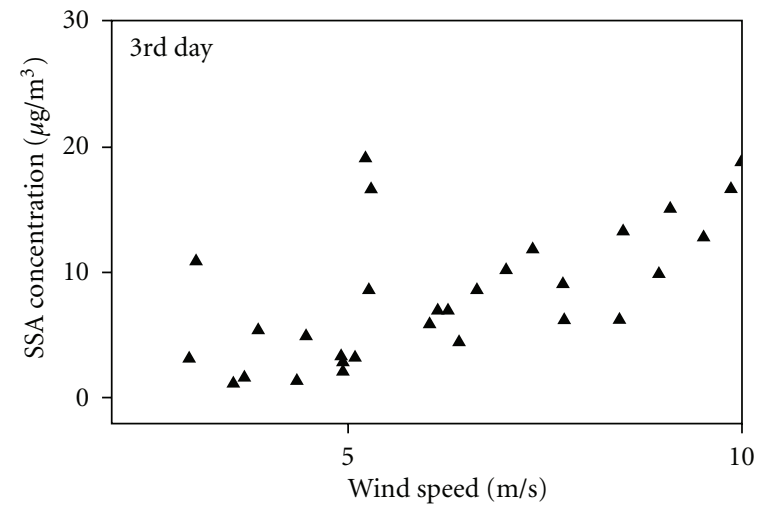

(e)

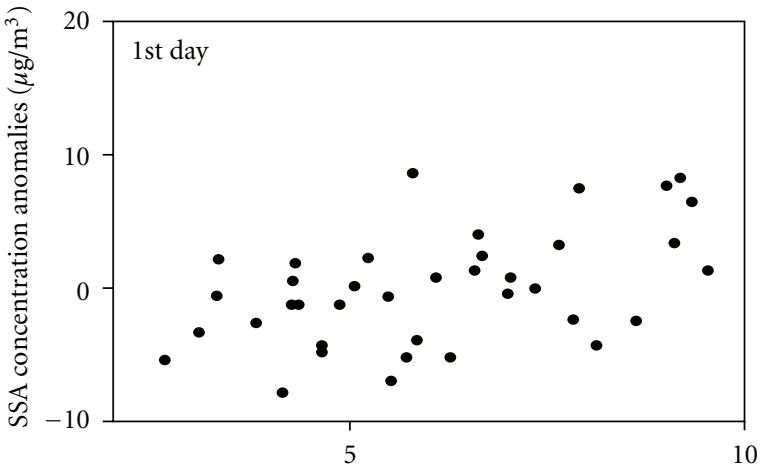

(b)

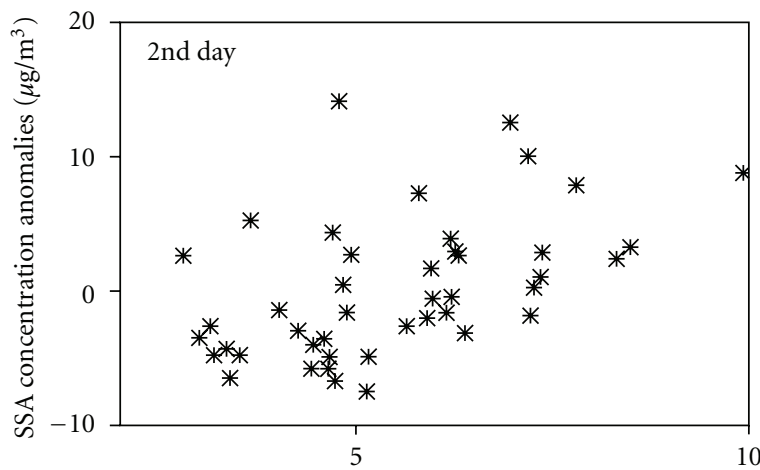

(d)

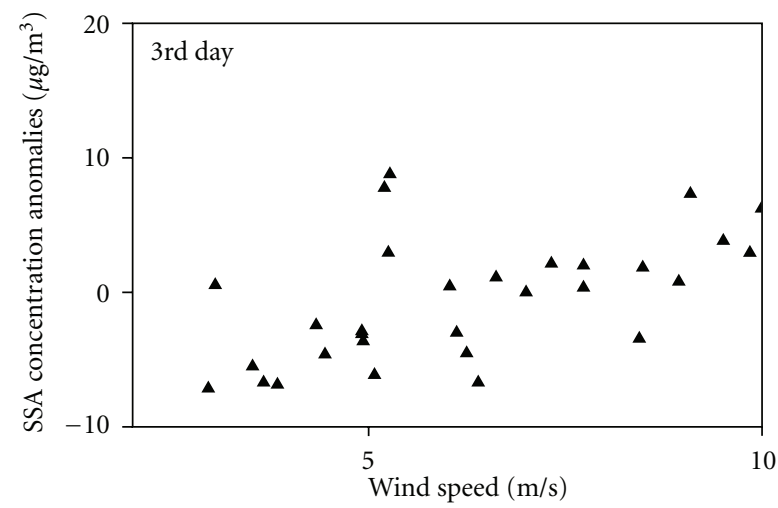

(f)

FIGURE 3: The data sets of (left panel) SSA concentrations and (right panel) their anomalies on the first, second, and third rainless days after rainfall.

on the first two days. Thus, SSA changes on the first and second days after rainfall best suit to understand the effect of rainfall on SSA time variations, as well as to illustrate our methodology. To this end, we analyzed SSA anomaly data sets created for available 28 couples of first and second consecutive days. As noted above, high random variability is observed in SSA anomalies on each of the specified days after rainfall. There could be several random factors contributing to the high variability in SSA concentration, such as high variability of sea-wave height at the same wind speed; effects of surf zone; wind gusts. The joint effect of the aforementioned factors resulted in random variability in measured SSA concentrations. The random variability could interfere with analyzing the desired nonrandom signal, which is the effect of rainfall on SSA time variation after rainfall.

Integrated processing of SSA data provided us with an opportunity to filter out random variability. We used the cumulative horizontal flux given by the following expression:

$$
F=\int C(v) d v
$$

where $C(v)\left[\mu \mathrm{g} / \mathrm{m}^{3}\right]$ stands for the SSA concentration anomaly measured under wind speed $v[\mathrm{~m} / \mathrm{s}]$. The integral $F$ was obtained over the entire wind speed range on the second 
day, $2.8 \mathrm{~m} / \mathrm{s}-9.9 \mathrm{~m} / \mathrm{s}$. The uncertainty of cumulative horizontal SSA flux $F=\int C(v) d v$ has been estimated, considering the uncertainty of SSA mass concentration measurements (PM10 measurements) of approximately $\pm 10 \%$ and the uncertainty of wind speed measurements at meteorological stations of approximately $\pm 1 \%$ (Figure 4 , the error bars).

The obtained changes in the cumulative horizontal SSA flux on the first and second consecutive days characterize SSA changes after removing random variability (Figure 4, the solid line). The transition from negative $F$ values on the first day to positive ones on the second day is clearly seen. The obtained negative $F$ value on the first day highlights the fact that, just after rainfall, SSA concentrations are mainly lower than their monthly mean level. Possible reasons, which cause negative $F$ values on the first day, are discussed in Section 4. The increase in $F$ values on the second day was observed despite the fact that average wind on the second day $(5.2 \mathrm{~m} / \mathrm{s})$ was lower than on the first day $(5.6 \mathrm{~m} / \mathrm{s})$. Note that the increase in $F$ values on the second day is consistent with the aforementioned predominance of positive DELTA $_{2-1}$ values over negative ones (Section 3.1).

Figure 4 (the dashed line) also shows changes in $F$ values on the 1st and 2nd days for all available SSA anomalies on the 1st and 2nd days (both consecutive and nonconsecutive). Both lines in Figure 4 show the increase in $F$ values on the second day with respect to that on the first day. Thus, the use of nonconsecutive days in the analysis of SSA variations after rainfall leads to similar results as those obtained for consecutive days.

\subsection{SSA Mass Concentration Oscillations after Rainfall}

3.4.1. SSA Mass Concentration Oscillations after Rainfall Based on the Whole Data Set. Similarly to our analysis of SSA changes on the 1st and 2nd days in Section 3.3, integrated processing was applied to SSA anomalies on the 1st, 2nd, 3rd, 4 th, and 5th days, in order to filter out random variability. We analyzed SSA measurements on nonconsecutive days after rainfall, as well as on consecutive days. Shown in Figure 5(a), changes in the cumulative SSA flux on the 1 st, 2nd, 3rd, 4th, and 5th days after rainfall demonstrate oscillations in SSA concentration after rainfall, obtained for wind speeds ranging from $2.8 \mathrm{~m} / \mathrm{s}$ to $9.9 \mathrm{~m} / \mathrm{s}$. Changes in $F$ values on the 1 st and 2 nd days after rainfall have been already discussed above in Section 3.3. On the 3rd day, the decrease in $F$ values, compared to the 2nd day, was observed (Figure 5(a)), in spite of the fact that average wind speed on the third day $(6.2 \mathrm{~m} / \mathrm{s})$ was higher than that of the second day $(5.5 \mathrm{~m} / \mathrm{s})$ (Table 2$)$. The obtained results indicate that the relationship between SSA production and dry deposition was essentially different on the first, second, and third days after rainfall. Changes in cumulative SSA flux on the fourth and fifth days display the further oscillating behavior of SSA concentration after rainfall. Note that the obtained SSA mass concentration oscillations on the 1st, $2 \mathrm{nd}, 3 \mathrm{rd}, 4 \mathrm{th}$, and 5 th days after rainfall are consistent with the aforementioned results for differences in SSA concentrations between consecutive days after rainfall (Section 3.1). Both approaches

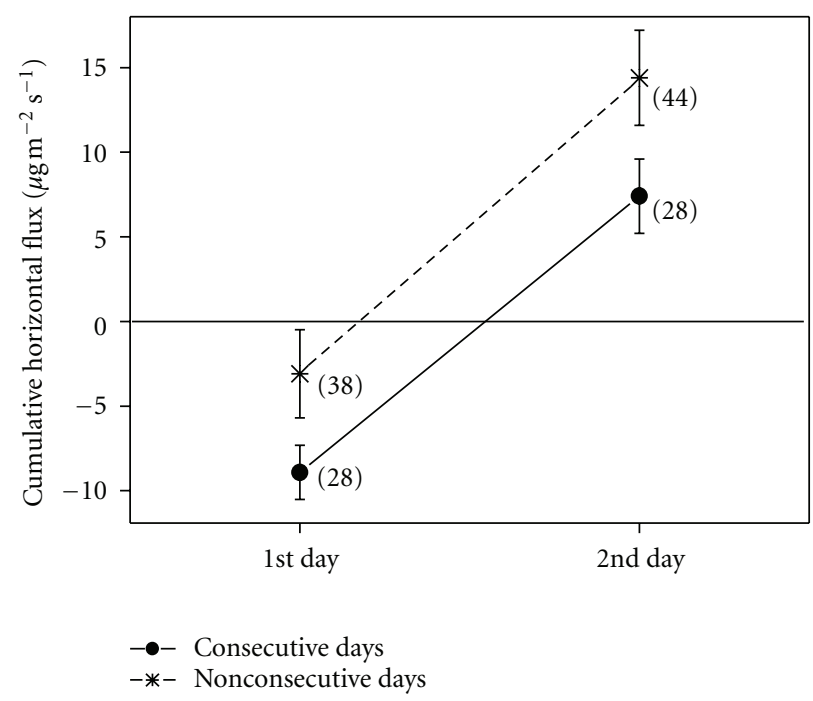

FIGURE 4: Changes in the cumulative horizontal SSA flux $F$ on (solid line) the consecutive first and second days after rainfall and on (dashed line) all available first and second days after rainfall (both consecutive and nonconsecutive), over wind speed range $2.8 \mathrm{~m} / \mathrm{s}-$ $9.9 \mathrm{~m} / \mathrm{s}$. The horizontal line represents the cumulative flux of zero. The error bars show the uncertainty of $F$ values. The figures in brackets indicate the number of days used. It is seen that the $F$ value on the second day is higher than on the first day for both consecutive and nonconsecutive days.

show the oscillating behavior of SSA mass concentration after rainfall.

3.4.2. SSA Changes on the $1 s t, 2 n d$, and 3rd Consecutive Days after Rainfall. There were 28 rain events with available SSA measurements on two-day periods, consisting of 1st and 2 nd consecutive days, and 23 rain events with SSA measurements on three-day periods, consisting of 1st, $2 \mathrm{nd}$, and 3rd consecutive days. This takes into account only consecutive days with wind speeds ranging from $2.8 \mathrm{~m} / \mathrm{s}$ to $9.9 \mathrm{~m} / \mathrm{s}$.

As the SSA mass concentration on the 1st and 2nd days has no connection with that of the subsequent 3rd day, the cumulative horizontal flux for those days was obtained on the basis of 28 rain events, as described in Section 3.3. By contrast, the SSA concentration on the 3rd day could depend on that of the 1st and 2 nd days. Therefore, for the 3rd day, integrated processing was applied to the aforementioned 23 rain events with available SSA measurements on the first, second, and third consecutive days. The obtained changes in cumulative horizontal flux $F$ on those consecutive days are shown in Figure 5(b). The SSA mass concentration oscillations were observed after rainfall. Those oscillations were characterized by a noticeable increase in $F$ values on the second day with respect to that of the first day. On the third day, a decrease in $F$ values was observed. Therefore, in spite of limited statistics available for consecutive days following each other in chronological order, the obtained SSA mass concentration oscillations after rainfall were similar to those for all available days (both consecutive and nonconsecutive days) (Figures 5(a) and 5(b)). 


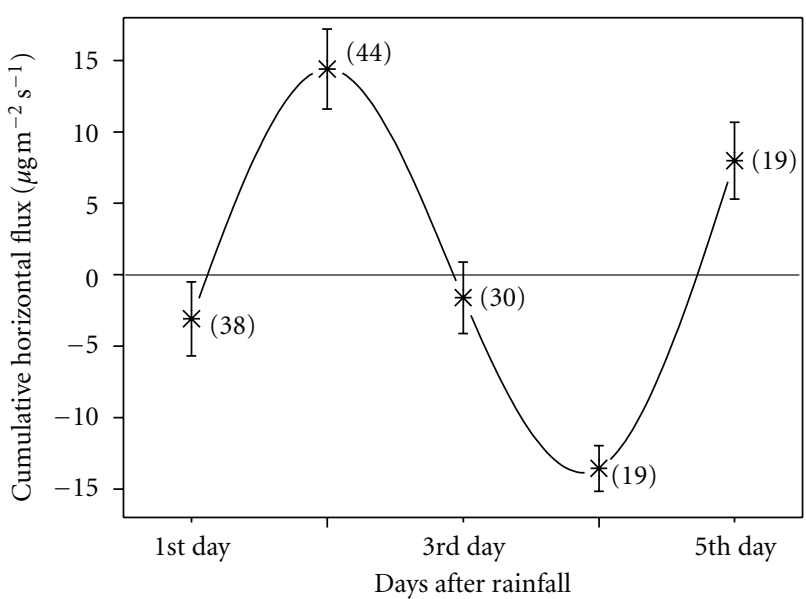

(a)

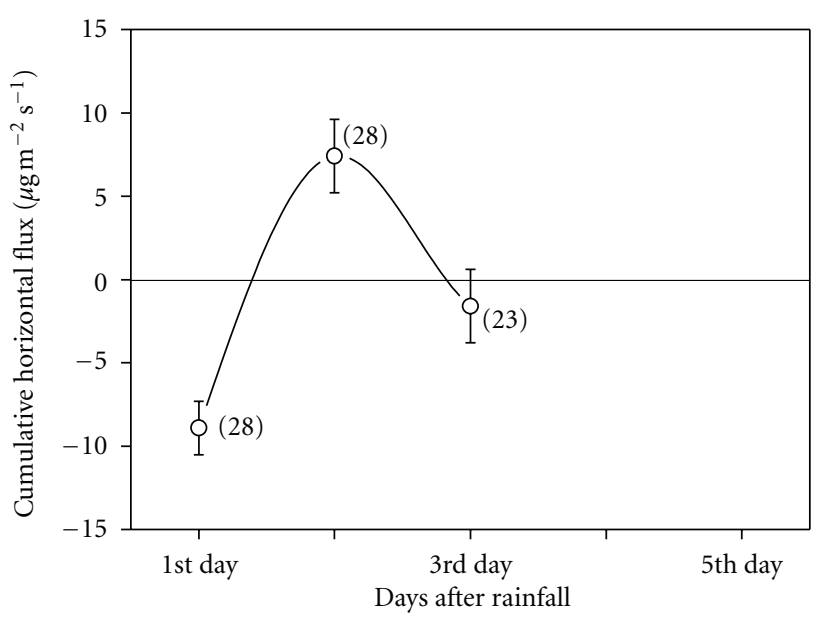

(b)

FIgure 5: (a) Changes in the cumulative horizontal SSA flux $F$ on the 1st, 2nd, 3rd, 4th, and 5th rainless days after rainfall (both consecutive and nonconsecutive days), over wind speed range $2.8 \mathrm{~m} / \mathrm{s}-9.9 \mathrm{~m} / \mathrm{s}$. (b) Changes in $F$ values after rainfall for rain events with available SSA measurements on consecutive days solely. The error bars show the uncertainty of $F$ values. The horizontal lines represent the cumulative flux of zero. The figures in brackets indicate the number of days used.

\section{Discussion and Conclusion}

The current experimental study focused on analyzing time variations of SSA mass concentration after rainfall, on the basis of long-term daily SSA measurements during the threeyear period 2006-2008, at the tiny Mediterranean island of Lampedusa. No experimental research on this topic has been carried out so far, at least to our knowledge. Considerable effort was made in order to collect and analyze SSA measurements, on a daily basis, over the three-year period.

To study the effect of rainfall on SSA time variations, we used the superposed epoch method, which has frequently been applied to studying the time variation of geophysical data $[9,10]$. We applied this approach to differing rainfall events related to different months and atmospheric/ sea conditions. In order to remove the effects of different initial conditions, we used SSA concentration anomalies, which are a deviation of daily concentrations from their monthly mean level. Local factors, such as sea-salt production in the surfzone, located in the vicinity of the monitoring site, can also contribute to measured sea-salt concentrations. However, the effects of those local factors on SSA concentration anomalies are random. Integrated processing was applied to SSA anomalies, in order to filter out random variability.

We analyzed SSA measurements taken on both consecutive and nonconsecutive days after rainfall (Section 2). We also used SSA measurements on nonconsecutive days in order to increase the available statistics and to base our results on a wide range of cases. Moreover, the same approach to the analysis of SSA mass concentration oscillations after rainfall was applied to rain events with available SSA measurements on consecutive days solely (Section 3.4). In spite of limited statistics, the obtained oscillations after rainfall were similar to those for all available days (both consecutive and nonconsecutive days).

Observational evidence of SSA mass concentration oscillations after rainfall was obtained for measurement conditions at the Lampedusa site. These conditions correspond to wind speeds ranging from $2.8 \mathrm{~m} / \mathrm{s}$ to $9.9 \mathrm{~m} / \mathrm{s}$ and daily accumulated rainfall from $0.5 \mathrm{~mm}$ to $44.9 \mathrm{~mm}$. We found that the obtained cumulative horizontal SSA flux $(F)$ on the second day was higher than on the first day, and $F$ on the third day was lower than on the second day. $F$ variations on the fourth and fifth days show further oscillating behaviour of SSA concentrations after rainfall.

The obtained negative $F$ value on the first day after rainfall points to SSA mass concentrations lower than their monthly mean level. The most plausible reason for negative $F$ value on the first day is wet removal of sea-salt aerosol during the rainfall period. One could assume that the presence of rainfall not only provides the removal of SSA by wet deposition but also might affect the sea surface microlayer by adding a large amount of fresh water. This could affect sea-salt aerosol production itself.

The increase in cumulative flux on the second day was not caused by an increase in wind speed: the increase was observed despite the fact that the average wind speed on the second day was lower than that of the first day (Table 2). It is reasonable to suggest that SSA concentration on the second day included not only SSA produced by wind on that day, but also particles remaining in the atmosphere from the first day.

Furthermore, on the third day, a decrease in $F$ value was observed, in spite of the fact that average wind speed on the third day was higher than that of the second day (Table 2). This indicates that, on the third day, dry deposition dominated SSA production. The obtained results highlight the fact that the relationship between SSA production and dry deposition was essentially different on the first, second, and third days after rainfall. The same applies to the fourth and fifth days when further SSA mass concentration oscillations were observed. One could assume that the obtained twoday interval between the maximum on the 2 nd day and the minimum on the 4 th day (approximately the half-period of 
SSA mass concentration oscillations) corresponds to the lifespan of SSA particles.

Consistent results were obtained for SSA mass concentration oscillations on the 1 st, $2 \mathrm{nd}$, $3 \mathrm{rd}$, 4 th, and 5 th days after rainfall by using two independent approaches: (a) by analyzing differences between SSA concentrations on consecutive days in the presence of random variability (Section 3.1) and (b) by integrated processing which eliminated random variability (Sections 3.2-3.4). Both approaches show the oscillating behavior of SSA concentration after rainfall and, thereby, the two approaches support each other.

The investigation of SSA mass concentration oscillations after rainfall is essential for a deeper understanding of the process of SSA loading in the atmospheric boundary layer. The knowledge of these oscillations is also important for validating rainout parameterization in existing sea-salt aerosol and climate models. Further research is needed in order to understand the physical mechanisms responsible for SSA mass concentration oscillations after rainfall.

\section{References}

[1] D. C. Blanchard, "The production, distribution, and bacterial enrichment of the sea-salt aerosol," in Air-Sea Exchange of Gases and Particles, P. Liss and W. Slinn, Eds., pp. 407-454, Springer, Berlin, Germany, 1983.

[2] G. De Leeuw, E. L. Andreas, M. D. Anguelova et al., "Production flux of sea spray aerosol," Reviews of Geophysics, vol. 49, no. 2, Article ID RG2001, 2011.

[3] E. R. Lewis and S. E. Schwartz, Sea Salt Aerosol Production: Mechanisms, Methods, Measurements, and Models-A Critical Review, AGU, Washington, DC, USA, 2004.

[4] C. D. O'Dowd, M. H. Smith, I. E. Consterdine, and J. A. Lowe, "Marine aerosol, sea-salt, and the marine sulphur cycle: a short review," Atmospheric Environment, vol. 31, no. 1, pp. 73-80, 1997.

[5] P. Warneck, Chemistry of the Natural Atmosphere, Academic Press, San Diego, Calif, USA, 1988.

[6] A. D. Clarke, S. R. Owens, and J. Zhou, "An ultrafine sea-salt flux from breaking waves: implications for cloud condensation nuclei in the remote marine atmosphere," Journal of Geophysical Research D, vol. 111, no. 6, Article ID D06202, 2006.

[7] F. Giorgi and W. L. Chameides, "The rainout parameterization in a photochemical model," Journal of Geophical Research, vol. 90, no. 5, pp. 7872-7880, 1985.

[8] F. Giorgi and W. L. Chameides, "Rainout lifetimes of highly soluble aerosols and gases as inferred from simulations with a general circulation model," Journal of Geophysical Research, vol. 91, no. D13, pp. 14367-14376, 1986.

[9] H. A. Panofsky and G. W. Brier, Some Applications of Statistics to Meteorology, Mineral Industries Extension Services, College of Mineral Industries, Pennsylvania State University, University Park, Pa, USA, 1968.

[10] C. F. Pérez, M. I. Gassmann, and M. Covi, "An evaluation of the airborne pollen-precipitation relationship with the superposed epoch method," Aerobiologia, vol. 25, no. 4, pp. 313-320, 2009.

[11] A. Clarke, V. Kapustin, S. Howell et al., "Sea-salt size distributions from breaking waves: Implications for marine production and optical extinction measurements during SEAS," Journal of Atmospheric and Oceanic Technology, vol. 20, pp. 1362-1374, 2003.
[12] H. J. M. Bowen, Environmental Chemistry of the Elements, Academic Press, San Diego, Calif, USA, 1979.

[13] P. K. Quinn, T. S. Bates, D. J. Coffman et al., "A comparison of aerosol chemical and optical properties from the 1st and 2nd aerosol characterization experiments," Tellus, Series B: Chemical and Physical Meteorology, vol. 52, no. 2, pp. 239-257, 2000.

[14] O. W. Wingenter, D. R. Blake, N. J. Blake et al., "Tropospheric hydroxyl and atomic chlorine concentrations, and mixing timescales determined from hydrocarbon and halocarbon measurements made over the Southern Ocean," Journal of Geophysical Research D, vol. 104, no. 17, pp. 21819-21828, 1999.

[15] S. Becagli, C. Ghedini, S. Peeters et al., "MBAS (Methylene Blue Active Substances) and LAS (Linear Alkylbenzene Sulphonates) in Mediterranean coastal aerosols: sources and transport processes," Atmospheric Environment, vol. 45, no. 37, pp. 6788-6801, 2011.

[16] I. Fattori, S. Becagli, S. Bellandi et al., "Chemical composition and physical features of summer aerosol at Terra Nova Bay and Dome C, Antarctica," Journal of Environmental Monitoring, vol. 7, no. 12, pp. 1265-1274, 2005.

[17] R. Udisti, S. Becagli, S. Benassai et al., "Atmosphere-snow interaction by comparison between aerosol and uppermost snow layers composition at Dome C, East Antarctica," Annals of Glaciology, vol. 39, pp. 53-61, 2004.

[18] P. Kishcha, S. Nickovic, B. Starobinets et al., "Sea-salt aerosol forecasts compared with daily measurements at the island of Lampedusa (Central Mediterranean)," Atmospheric Research, vol. 100, no. 1, pp. 28-35, 2011.

[19] G. J. Huffman, R. F. Adler, D. T. Bolvin et al., "The TRMM multisatellite precipitation analysis (TMPA): quasi-global, multiyear, combined-sensor precipitation estimates at fine scales," Journal of Hydrometeorology, vol. 8, no. 1, pp. 38-55, 2007. 

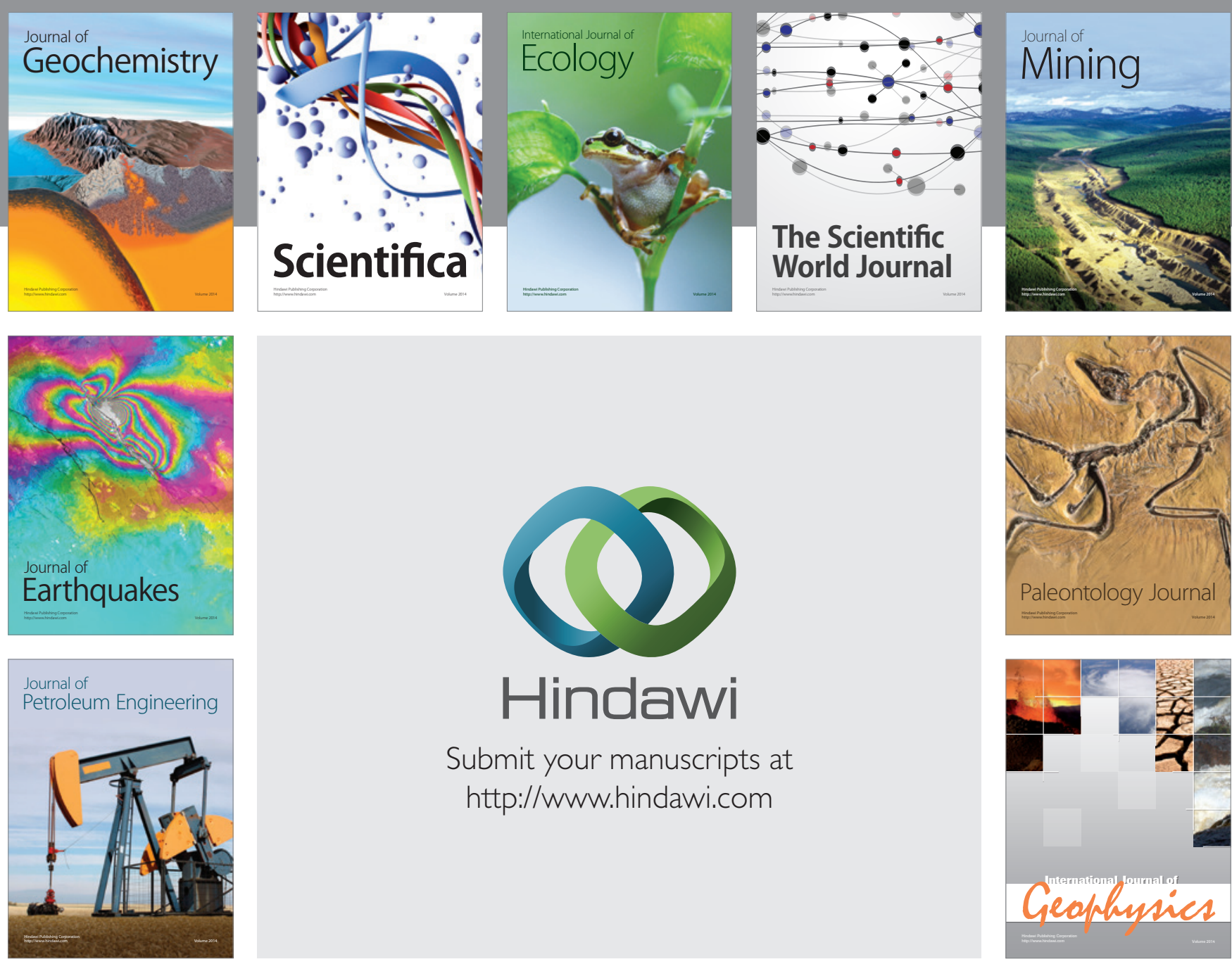

Submit your manuscripts at

http://www.hindawi.com
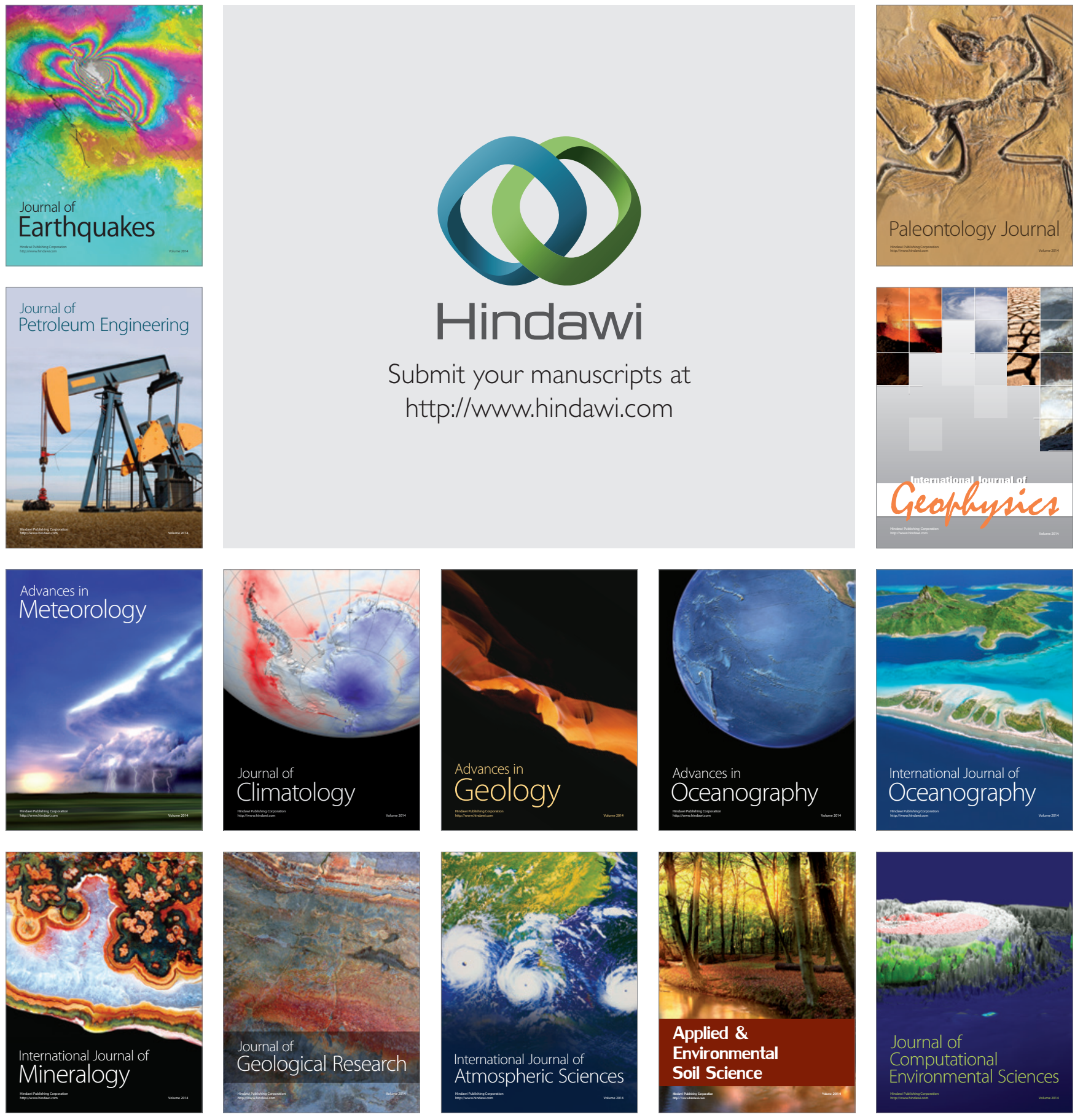